\title{
ALTERAÇÕES ESTRUTURAIS IN VIVO DOS ISÔMEROS TODO-TRANS, 9-CIS E 13-CIS DO $\beta$-CAROTENO ${ }^{1}$
}

\author{
Maria Aparecida Lopes da COSTA², Claudia Isabel ORTEGA-FLORES ${ }^{2}$, Marilene De Vuono Camargo PENTEADO ${ }^{3, *}$
}

\section{RESUMO}

Com o objetivo de verificar alterações estruturais nos isômeros todo-trans, 9- e 13-cis do $\beta$-caroteno foi realizado um ensaio biológico baseado no modelo de esgotamento das reservas hepáticas de carotenóides em ratos. Animais depletados desses carotenóides receberam, durante quinze dias, os isômeros puros todo-trans, 9-cis e 13-cis do $\beta$-caroteno. Ao final deste periodo, verificou-se a ocorrência de reisomerização in vivo desses isômeros, a partir da quantificação dos mesmos depositados no figado dos animais. Foi observada re-isomerização do 9-cis em todo-trans, do todo-trans em 9-cis, do 13-cis em 9-cis e todo-trans. O 13-cis foi mais susceptivel à isomerização que o 9-cis, pois este último passou a todo-trans e nunca a 13-cis. Já o 13-cis, tanto pode se transformar em 9-cis quanto em todo-trans. Palavras-chave: re-isomerização; $\beta$-caroteno; isômeros; carotenóides.

\section{SUMMARY}

IN-VIVO STRUCTURAL ALTERATIONS OF THE ALL-TRANS, 9-CIS AND 13-CIS OF $\beta$-CAROTENE ISOMERS. A biological assay was conducted in order to verify the possible structural interconversion of the 9 -cis, 13 -cis and all-trans $\beta$-carotene isomers. The different $\beta$-carotene isomers (either all-trans $\beta$-carotene, 9-cis $\beta$-carotene or 13-cis $\beta$-carotene) were administered for fifteen days to rats that had been previously depleted of liver carotenoids. It was possible to verify the in vivo re-isomerization of the isomers. The 9-cis $\beta$-carotene isomer can be converted into all-trans $\beta$-carotene, the latter re-isomerized into 9-cis $\beta$-carotene, and the 13-cis $\beta$-carotene modified into 9 -cis $\beta$-carotene and all-trans $\beta$-carotene. From these results it can be concluded that the 13-cis isomer was more susceptible to isomerization than was the 9-cis $\beta$-carotene, because the latter could be isomerized into all-trans, but not into 13 -cis $\beta$-carotene, while the 13-cis can be either modified to 9-cis or to all-trans $\beta$-carotene.

Keywords: $\beta$-carotene; isomers; re-isomerization; carotenoids.

\section{1 - INTRODUÇÃO}

O $\beta$-caroteno existe naturalmente na configuração termodinamicamente mais estável e menos solúvel, a forma todo-trans. Contudo, a ocorrência natural de isômeros cis tem sido relatada com uma certa freqüência. Teoricamente, existiriam 272 possiveis isômeros do $\beta$-caroteno, porém, apenas 12 têm sido detectados [2].

SWEENEY e MARSH [26], trabalhando com hortaliças conseguiram separar o isômero todo-trans bem como seis isômeros cis do $\beta$-caroteno, a saber: neo $\beta$-caroteno $U$, neo $\beta$-caroteno $\mathrm{V}$, neo $\beta$-caroteno $\mathrm{B}$, neo $\beta$-caroteno $\mathrm{C}$, neo $\beta$-caroteno $D$ e neo $\beta$-caroteno $E$. Em muitas frutas e hortaliças, os únicos isômeros do $\beta$-caroteno presentes são o todo-trans, o neo $\beta$-caroteno U (9-cis) e o neo $\beta$-caroteno B (13-cis), sendo os dois primeiros os mais comumente encontrados [5, 8, 9, 17].

A isomerização cis-trans pode ocorrer durante o processamento e estocagem do alimento [7]. Devido ao seu sistema conjugado de duplas ligações, os carotenóides são estruturas altamente instáveis. O calor, a luz, os ácidos, o oxigênio e enzimas como lipoxigenase levam a alterações ou parcial destruição dos pigmentos. A exposição destes a tais agentes, resulta na formação de isômeros cis, epóxidos, diminuição da cor, perda da atividade próvitamínica A e quebra da cadeia [21].

\footnotetext{
Recebido para publicação em 19/06/2000. Aceito para publicação em 08/03/2002.

2. Curso de Pós-Graduação em Ciências dos Alimentos, Faculdade de Ciências Farmacêuticas - USP-SP.

3. Faculdade de Ciências Farmacêuticas - USP-SP-Depto. de Alimentos e Nutrição Expereimental. Av. Prof. Lineu Prestes, 580, Bl. 14. Cidade Universitária.CEP 05508-900.SãoPaulo.SP.E-mail: devuono@usp.br * A quem a correspondência deve ser enviada.
}

Tendo em vista que a absorção dos lipídeos ocorre em função da formação das micelas, a solubilização dos carotenóides nas micelas lipídicas do intestino é um pré-requisito para a absorção desses pigmentos. A composição isomérica do $\beta$-caroteno afeta a quantidade de carotenóide incorporado às micelas lipídicas. $\mathrm{O}$ isômero 9-cis do $\beta$-caroteno parece aumentar a incorporação do isômero todo-trans às micelas lipídicas do intestino de ratos [13].

GAZIANO et al. [10], estudaram a absorção e a incorporação dos isômeros 9-cis e todo-trans do $\beta$-caroteno nas lipoproteínas no plasma de humanos, e observaram que existe uma preferencial absorção e transporte do todo-trans em comparação com o 9-cis.

STAHL et al. [22], detectaram o isômero 9-cis no soro de humanos, porém, em quantidades traço. $\mathrm{O}$ isômero 9-cis do $\beta$-caroteno é absorvido, imediatamente transferido e acumulado em tecidos, não sendo por isto encontrado no soro [23, 24].

Outros possiveis mecanismos podem explicar a ausência do isômero 9-cis no plasma, como por exemplo: a ineficiente captação intestinal do isômero 9-cis em contraste com o todo-trans; a rápida degradação do 9-cis no trato-gastrointestinal; a rápida remoção desse isômero do plasma; a rápida conversão deste isômero em vitamina $\mathrm{A}$; ou a rápida transisomerização do 9-cis em todotrans [28].

Nos estudos realizados por LEVIN, BEN-AMOTZ e MOKADY [14] e BEN-AMOTZ et al. [4], animais acumulam os isômeros do $\beta$-caroteno diferentemente. Para estes autores, ratos acumulam preferencialmente o isômero todo-trans, enquanto que os galináceos acumulam 
o 9-cis $\beta$-caroteno. A presença deste último na dieta, permite um maior acúmulo do todo-trans nos tecidos dos ratos. Tais fatos devem acontecer em função das propriedades físico-químicas dos isômeros cis diferirem das do isômero todo-trans, particularmente aquelas relacionadas com solubilidade e cristalização [6].

Outras diferenças existentes entre os isômeros cis e todo-trans estão relacionadas com as outras funções desempenhadas pelos carotenóides, como por exemplo, a atuação como antioxidantes, uma vez que aparentemente o isômero 9-cis seria um antioxidante mais eficiente que o todo-trans [3].

Tendo em vista o acima exposto o objetivo desse trabalho foi verificar a ocorrência de re-isomerização dos isômeros todo-trans, 9 e 13-cis do $\beta$-caroteno, in vivo.

\section{2 - MATERIAL E MÉTODOS}

\section{1 - Delineamento experimental}

No ensaio biológico, foram utilizados ratos machos da linhagem Wistar (Rattus norvegicus, var. Albinos Rodentia mammalia), provenientes da colônia do Biotério da Faculdade de Ciências Farmacêuticas da Universidade de São Paulo.

Inicialmente, os animais foram depletados de carotenóides, conforme descrito a seguir. Durante 22 dias quinze ratas adultas amamentaram de oito a dez filhotes, sendo que destes, em média 8 eram machos e os demais fêmeas. As mães receberam ração à base de caseína deficiente em carotenóides. Ao final deste período, os filhotes foram separados das mães, pesados e agrupados em quatro grupos com sete animais em cada grupo.

Para assegurar a eficácia da depleção, todos os animais de cada grupo foram alojados em gaiolas individuais com bebedouro de plástico ou vidro e permaneceram durante dezessete dias recebendo a mesma dieta sem carotenóides. Esta fase correspondeu ao período de esgotamento das reservas hepáticas de carotenóides.

Ao término deste periodo, um grupo de animais foi sacrificado e os figados e sangue recolhidos para posterior análise. Este grupo foi denominado Grupo Um.

A partir deste momento, durante 15 dias os animais passaram a receber, por entubação gástrica a cada dois dias, os isômeros todo-trans, 9-cis e 13-cis do $\beta$-caroteno dissolvidos em $0,5 \mathrm{~mL}$ de óleo de milho. Os grupos formados foram denominados de grupo $\beta$-caroteno todotrans, 9-cis e 13-cis, respectivamente.

Os animais receberam $45 \mu \mathrm{g} /$ dia de $\beta$-caroteno todotrans, $82 \mu \mathrm{g} /$ dia de isômero 9-cis do $\beta$-caroteno e $68 \mu \mathrm{g} /$ dia de isômero 13 -cis do $\beta$-caroteno para os grupos $\beta$-caroteno todo-trans, 9-cis e 13-cis, respectivamente. Tais teores foram calculados de modo a suprir as necessidades recomendadas por REEVES et al. [19] para cada dois dias. No caso dos isômeros cis, os cálculos foram feitos levando-se em consideração as biopotências obtidas por SWEENEY E MARSH [25].
Ao final deste periodo todos os animais foram sacrificados e os figados recolhidos para análise em cromatografia liquida de alta eficiência (CLAE).

Durante todo experimento os animais receberam ad libitum água e ração sem carotenóides.

\section{2 - Obtenção dos carotenóides fornecidos aos ani- mais}

Os isômeros de $\beta$-caroteno fornecidos aos animais foram extraídos de folhas de couve-flor (Brassica oleracea L.) no Laboratório de Análise de Alimentos da Faculdade de Ciências Farmacêuticas da Universidade de São Paulo.

Os procedimentos de extração e separação dos isômeros do $\beta$-caroteno foram feitos de acordo com o método de RODRIGUEZ et al. [20], com algumas modificações conforme descrito em COSTA e PENTEADO [9].

\section{3 - Colheita e extração das amostras}

Para se proceder a retirada do figado, os animais foram anestesiados por inalação de éter etílico p. a. Os figados foram retirados, lavados em solução salina 0,9\% $(\mathrm{p} / \mathrm{v})$ resfriada, secos em papel de filtro, pesados, subdivididos em pedaços de até $3 g$, embalados em papel alumínio, congelados em nitrogênio líquido e armazenados em freezer $\mathrm{a}-70^{\circ} \mathrm{C}$ até a análise.

\section{4 - Análise de retinol, $\beta$-caroteno e isômeros no material biológico}

Os procedimentos de saponificação e extração dos isômeros do $\beta$-caroteno presentes nos figados foram baseados no trabalho de AL-ABDULALY e SIMPSON [1]. Tais procedimentos estão descritos resumidamente a seguir:

Em torno de 2 gramas de figado foram pesados em tubo de ensaio e homogeneizados utilizando-se um triturador tipo Turrax, usando-se o mínimo possivel de água. Em seguida, adicionou-se cerca de $30 \mathrm{~mL}$ de $\mathrm{KOH}$ metanólico 30\% (p/v). A mistura permaneceu durante uma noite, no escuro, sob nitrogênio e à temperatura ambiente.

Ao final desse periodo, a mistura foi transferida para um erlenmeyer contendo $50 \mathrm{~mL}$ de éter etílico e agitado mecanicamente durante 15 minutos. Após este tempo, a mistura foi transferida para um funil de separação e a fase metanólica foi descartada. O álcali residual presente na fase etérea foi removido através de sucessivas lavagens com água destilada. Posteriormente, a solução foi transferida para erlenmeyer e a água remanescente foi retirada com a adição de sulfato de sódio anidro. O éter etílico contendo o $\beta$-caroteno extraído foi então transferido para um balão e evaporado em rota-evaporador, a vácuo.

Após a secura, o balão foi lavado com $2 \mathrm{~mL}$ de éter etílico e a solução transferida para um tubo de ensaio. O éter etílico foi evaporado por nitrogênio e ao resíduo adicionou-se de 0,3 a 0,5mL de metanol, para determina- 
ção de $\beta$-caroteno e isômeros. Antes da injeção no CLAE as amostras foram filtradas com membrana de $0,45 \mu \mathrm{m}$.

\section{5 - Condições cromatográficas para análise dos isô- meros de $\beta$-caroteno}

O $\beta$-caroteno presente nos figados foi determinado através de cromatografia líquida de fase reversa. A coluna de separação era $\mathrm{C}_{18}$, contendo partículas de $5 \mu \mathrm{m}$, com 4,6 mm de diâmetro interno e $25 \mathrm{~cm}$ de comprimento, marca Vydac 201 TP 54. A fase móvel era uma mistura de metanol:acetonitrila:água $(88: 9: 3 \mathrm{v} / \mathrm{v} / \mathrm{v})$. O detector era UV/visivel e o comprimento de onda máximo na quantificação dos isômeros era de $452 \mathrm{~nm}$. O fluxo das injeções da fase móvel foi de $2,0 \mathrm{~mL} / \mathrm{min}$. e o volume de injeção foi de $20 \mu \mathrm{L}$ fixado pelo looping.

\section{6 - Identificação e quantificação dos isômeros do $\beta$-caroteno}

Os compostos foram identificados através da comparação entre os tempos de retenção dos seus picos e os tempos de retenção dos picos dos padrões correspondentes e dos seus espectros cromatográficos. A quantificação foi feita utilizando-se as respectivas curvas de calibração.

\section{7 - Análise estatística}

As análises dos resultados obtidos durante a fase de testes foram feitas utilizando-se o teste de KruskallWallis, que equivale a ANOVA (One-Way Analysis of Variance) não paramétrica. Este é o teste indicado para se verificar a homogeneidade dos grupos em que o $\mathrm{n}<30$, através da análise múltipla das variáveis.

Quando se verificava diferença estatisticamente significativa foi aplicado o teste de Mann-Whitney (não paramétrico). Todas as análises foram realizadas com nivel de significância de $5 \%(p<0,05)[11]$.

\section{3 - RESULTADOS E DISCUSSÃO}

Para se determinar os teores de retinol e $\beta$-caroteno hepático, foi analisado, sempre que possivel apenas o lóbulo direito do animal. Este tipo de cuidado foi tomado para se evitar a análise de amostras muito heterogêneas. OLSON [16], encontrou uma distribuição não homogênea de retinol no figado.

Na Tabela 1 estão as contribuições dos isômeros todotrans, 9 e 13-cis no teor total de $\beta$-caroteno de figado.

$\mathrm{O}$ isômero todo-trans foi o predominante nas amostras de figado dos grupos que receberam $\beta$-caroteno como fonte de vitamina A. É interessante observar o aparecimento do isômero 9-cis, mesmo que em pequena porcentagem $(4,1 \%)$, nos figados de animais que haviam recebido apenas o isômero todo-trans, indicando claramente que houve uma isomerização do todo-trans em 9-cis. O inverso, ou seja, a re-isomerização do 9-cis em todo-trans, ocorreu em maior proporção, pois foi considerável a porcentagem de todo-trans $(65,2 \%)$ no figado do grupo que recebeu apenas o 9-cis.
TABELA 1. Porcentagem da contribuição dos isômeros todotrans, 9 e 13-cis nos teores de $\beta$-caroteno dos fïgados de ratos, analisados após os períodos de desmame, depleção e repleção. repleção.

\begin{tabular}{llll}
\hline Grupos & \multicolumn{3}{c}{ Isômeros (\%) } \\
\cline { 2 - 3 } & $9-c i s$ & $13-c i s$ & todo-trans \\
\hline
\end{tabular}

$\begin{array}{lccc}\text { Grupo Um } & \text { nd } & \text { nd } & 100 \\ \beta \text { todo-trans }^{1} & 4,1 & \text { nd } & 95,9 \\ 9-c i s^{1} & 34,8 & \text { nd } & 65,2 \\ 13-c i s^{1} & 25,2 & 12,6 & 62,2\end{array}$

nd = não detectado

${ }^{1}$ grupos correspondentes ao periodo de repleção de vitamina A

Tem sido levantada a possibilidade do isômero 9-cis primeiramente passar a todo-trans, e este ser posteriormente convertido em retinol, ao invés da conversão direta do isômero cis em retinol [12, 18].

YOU et al. [26], para estudarem a absorção e metabolismo do 9 -cis $\beta$-caroteno, forneceram para 3 individuos $1,0 \mathrm{mg}$ de $\beta$-caroteno, com a seguinte proporção, $99,4 \%$ de 9 -cis e $0,6 \%$ de todo-trans. Os resultados obtidos sugeriram que ocorreu uma transisomerização do 9-cis em todo-trans.

YOU et al. [29], estudaram o metabolismo de isômero 9-cis marcado com carbono 13 em humanos, e encontraram dados que sugerem que este isômero pode facilitar a absorção do todo-trans ou ser parcialmente isomerizado formando este último, porém, não pode ser extensivamente absorvido nem diretamente metabolizado em 9-cis retinol.

TAMAI et al. [27], acreditam que o isômero 9-cis do $\beta$-caroteno não é absorvido diretamente através do intestino, porém pode ser encontrado nas células. A explicação para isso seria a isomerização do todo-trans em 9cis, que ocorreria durante e após a absorção. Porém, como pode-se constatar neste trabalho, esse isômero pode ser absorvido através do intestino, a menos que ele tenha sido re-isomerizado no trato-gastrointestinal antes de ser absorvido, e depois voltado à forma de 9-cis.

Nos figados do grupo que recebeu 13-cis foi encontrada a mistura dos três isômeros, sendo que a porcentagem do isômero 9-cis encontrada foi maior que a do próprio 13-cis, indicando que houve re-isomerização.

Duas hipóteses são sugeridas: na primeira hipótese, o 13-cis $\beta$-caroteno sofreria isomerização, formando todotrans e 9-cis, concomitantemente. Na segunda hipótese, o 13-cis $\beta$-caroteno passaria a todo-trans e este por sua vez se isomerizaria em 9-cis $\beta$-caroteno.

Acredita-se que a primeira hipótese é a mais viável, pois, parece que são necessários mais passos para que a segunda hipótese aconteça. Além disso, a porcentagem de 9-cis $\beta$-caroteno formada oriunda do 13-cis é alta ( $\mathrm{Ta}$ bela 1). Se a segunda hipótese ocorresse, encontrar-se- 
ia uma menor porcentagem de 9-cis no grupo que recebeu 13-cis. De acordo com os resultados obtidos com o grupo que recebeu $100 \%$ de todo-trans, menos de $5 \%$ do todo-trans se converteu em 9-cis. Assim, parece pouco provável que o 13-cis $\beta$-caroteno passe a todo-trans e que este passe a 9-cis. Entretanto, as duas hipóteses podem ocorrer ao mesmo tempo.

NAGAO e OLSON [15], também observaram após a administração dos isômeros cis do $\beta$-caroteno a ratos a formação de diferentes isômeros de retinaldeído. Quando a fonte era o isômero $\beta$-caroteno todo-trans, $72 \%$ do retinaldeído formado era todo-trans, $25 \%$ era 13 -cis e $3 \%$ era 9-cis. Quando era fornecido o isômero 9-cis $\beta$ caroteno, 64\% do retinaldeído formado era todo-trans e $22 \%$ era 9-cis e não apareceu o 13-cis retinaldeído. Quando a fonte era o 13 -cis $\beta$-caroteno, as proporções eram de $74 \%, 18 \%$ e $7 \%$ de todo-trans, 13 -cis e 9 -cis retinaldeído, respectivamente. Para estes autores, o caminho de conversão do isômero 9 -cis do $\beta$-caroteno em 9 -cis e todo-trans retinaldeído é direto. Sobre a conversão do 13-cis, estes autores sugerem dois caminhos: 1) 13-cis $\beta$-caroteno passa a 13 -cis retinaldeído que por sua vez passa a retinaldeído todo-trans, e 2) 13-cis $\beta$-caroteno passa a $\beta$-caroteno todo-trans que passa a todo-trans retinaldeído que passa a 13-cis retinaldeído. Como a proporção de 13-cis retinaldeído formado a partir do $\beta$-caroteno todo-trans era maior do que a partir do 13-cis $\beta$ caroteno, os autores acreditam o segundo caminho é o mais conveniente.

Aparentemente, o isômero 13-cis é mais susceptivel à isomerização que o 9-cis, pois nos figados dos grupos que receberam 9-cis puro, não foi detectado o 13-cis, e nos grupos que receberam 13-cis foi detectado o isômero 9-cis.

A metodologia empregada nesse estudo não permitiu verificar em qual fase do metabolismo ocorreu isomerização nem se a absorção do $\beta$-caroteno foi influenciada pelas formas cis da molécula, porém parece que tal fato ocorreu em algum momento.

Conforme observado anteriormente, a isomerização aconteceu de modo mais acentuado nos grupos que receberam o isômero 13-cis.

\section{4 - CONCLUSÕES}

Os resultados obtidos no presente trabalho permitem concluir que o isômero todo-trans do $\beta$-caroteno foi a principal forma isomérica encontrada no figado de ratos que receberam carotenóides como fonte de vitamina A. Ocorreu re-isomerização do 9-cis em todo-trans, do todo-trans em 9-cis, do 13-cis em 9-cis e todo-trans. O 13 -cis $\beta$-caroteno é mais susceptivel à isomerização que o 9-cis $\beta$-caroteno, pois este último passa a todo-trans e nunca a 13-cis, já o 13-cis tanto pode se transformar em 9-cis quanto em todo-trans.

Os isômeros $\beta$-caroteno todo-trans, 9-cis e 13-cis, administrados por via intragástrica, sofrem alterações estruturais durante o seu metabolismo.

\section{5 - REFERÊNCIAS BIBLIOGRÁFICAS*}

[1] AL-ABDULALY, A. B., SIMPSON, K. L. Reversed-phase flash column chromatography for the determination of retinol in some foods. J. Micronutr. Anal., Barking, v. 5, p. 161-9, 1989.

[2] BAUERNFEIND, J. C. Carotenoid vitamin A precursors and analogs in foods and feeds. J. Agric. Food Chem., Washington, v. 20, n. 3, p. 456-73, 1972.

[3] BEN-AMOTZ, A., LEVY, Y. Bioavailability of a natural isomer mixture compared with synthetic all-trans $\beta$-carotene in human serum. Am. J. Clin. Nutr., Bethesda, v. 63, p. 729-34, 1996.

[4] BEN-AMOTZ, A., MOKADY, S., EDELSTEIN S., AVRON, M. Bioavailability of a natural isomer mixture as compared with synthetic all-trans- $\beta$-carotene in rats and chicks. J. Nutr., Philadelphia, v.119, p. 1013-9, 1989.

[5] BIANCHINI, R. Carotenóides dos pimentões amarelos (Capsicum annuum, L.). Caracterização e verificação de mudanças com o cozimento. São Paulo, 1993. 101p. (Dissertação - Mestrado) - Faculdade de Ciências Farmacêuticas (USP).

[6] BRITTON, G. Structure and properties of carotenoids in relation to function. FASEB J., Bethesda, v. 9, n. 15, p. 1551-8, 1995.

[7] CHANDLER, L. A., SCHWARTZ, S. J. Isomerization and losses of trans- $\beta$-carotene in sweet potatoes as affected by processing treatments. J. Agric. Food Chem., Washington, v. 36, n. 1, p. 129-33, 1988.

[8] CHANDLER, L. A., SCHWARTZ, S. J. HPLC separation of cistrans carotene isomers in fresh and processed fruits and vegetables. J. Food Sci., Chicago, v. 52, n. 3, p. 669-72, 1987.

[9] COSTA, M. A. L., PENTEADO, M. V. C. Alterações decorrentes de dois tipos de cozimento sobre os teores de carotenóides pró-vitamínicos A em escarolas (Cichorium endivia L.). Rev. Farm. Bioquím. Univ. São Paulo, São Paulo, v. 32, n. 2, p. 95-100, 1996.

[10] GAZIANO, J. M., JOHNSON, E. J., RUSSEL, R. M., MANSON, J. E., STAMPFER, M. J., RIDKER, P. M., FREI, B., HENNEKENS, C. H., KRINSKY, N. I. Discrimination in absorption or transport of $\beta$-carotene isomers after oral supplementation with either all-trans or 9-cis- $\beta$-carotene. Am. J. Clin. Nutr., Bethesda, v. 61, p. 1248-52, 1995.

[11] GRAPHPAD InStat tm. Copyright (C) 1990-1993 GraphPad Software. V2.01. Cipolla-Neto, Univ. of São Paulo. 930675s. [Programa de computador].

[12] JENSEN, C. D., HOWES, T. W., SPILLER, G. A., PATTISON, T. S., WHITTAM, J. H., SCALA, J. Observations of the effects of ingesting cis- and trans-beta-carotene isomers on human serum concentrations. Nutr. Rep. Int., Los Altos, v. 35, n. 2, p. 413-23, 1987.

[13] LEVIN, G., MOKADY, S. Incorporation of all-trans or 9-cis$\beta$-carotene into mixed micelles in vitro. Lipids, Champaign, v. 30, p. 177-9, 1995.

[14] LEVIN, G., BEN-AMOTZ, A., MOKADY, S. Liver accumulation of solube all-trans ou 9 -cis- $\beta$-carotene in rats and chicks. Comp. Biochem. Physiol., Oxford, v. 107A, n. 1, p. 2037, 1994.

* De acordo com a norma NBR 6023/89 preconizada pela ASSOCIAÇÃO BRASILEIRA DE NORMAS TÉCNICAS (ABNT). As abreviaturas dos títulos dos periódicos seguem o CHEMICAL ABSTRACTS SER VICE SOURCE INDEX (CASSI) 1996 
[15] NAGAO, A., OLSON, J. A. Enzymatic formation of 9-cis, 13cis, and all-trans retinaldeídos from isomers of $\beta$-carotene. FASEB J., Bethesda, v. 8, p. 968-73, 1994.

[16] OLSON, J. A. A simple dual assay for vitamin A and carotenoids in human liver. Nutr. Rep. Int., Los Altos, v. 19, n. 6, p. 807-13, 1979.

[17] ORTEGA-Flores, C. I., PEnTEAdo, M. V. C. Carotenóides com atividade pró-vitaminica A em cultivares de mandioca (Manihot esculenta Crantz) do Estado de São Paulo. Rev. Farm. Bioquím. Univ. São Paulo, São Paulo, v. 28, n. 1, p. 51-60, 1992.

[18] PARKER, R. S. Absorption, metabolism, and transport of carotenoids. FASEB J., Bethesda, v. 10, p. 542-51, 1996.

[19] REEvES, P. G., NIELSEN, F. H., FAHEY Jr., G. C. AIN-93 Purified diets for laboratory rodents: final report of the American Institute of Nutrition Ad Hoc Writing Committee on the Reformulation of the AIN-76A Rodent Diet. J. Nutr., Philadelphia, v. 123, p. 1939-51, 1993.

[20] RODRIGUEZ, D. B., RAYMUNDO, L. C., LEE, T., SIMPSON, K. L., CHICHESTER, C. O. Carotenoid pigment changes in ripenning Momordica charantia fruits. Ann. Bot., London, v. 49, p. 615-24, 1976.

[21] SIMPSON, K. L., CHICHESTER, C. O. Metabolism and nutritional significance of carotenoids. Annu. Rev. Nutr., Palo Alto, v. 1, p. 351-74, 1981.

[22] STAHL, W., SUNDQUIST, A. R., HANUSCH, M., SCHWARZ, W., SIES, H. Separation of $\beta$-carotene and lycopene geometrical isomers in biological samples. Clin. Chem., Winton Salem, v. 39, n. 5, p. 810-4, 1993a.

[23] STAHL, W., SCHWARZ, W., SIES, H. Human serum concentrations of all-trans $\mathrm{b}$ and a-carotene but not 9- cis $\beta$-carotene increase upon ingestion of a natural isomer mixture obtained from Dunaliella salina (Betatene). J. Nutr., Philadelphia, v. 123, 847-51, 1993b.

[24] STAHL, W., SCHWARZ, W., SUNDQUIST, A. R., SIES, H. cis-trans isomers of lycopene and $\beta$-carotente in human serum and tissues. Arch. Biochem. Biophys., New York, v. 294, n. 1, p. 173-7, 1992.

[25] SWENEY, J. P. MARSH, A. C. Liver storage of vitamin A in rats fed carotene stereoisomers. J. Nutr., Philadelphia, v. 103, p. 20-5, 1973.

[26] SWEENEY, J. P., MARSH, A. C. Vitamins and other nutrients. Separation of carotene stereoisomers in vegetables. J. Assoc. Off. Anal. Chem., Washington, v. 53, n. 5, 937-40, 1970.

[27] TAMAI, H., MORINOBU, T., MURATA, T., MANAGO, M., MINO, M. 9-cis- $\beta$-carotene in human plasma and blood cells after ingestion of $\beta$-carotene. Lipids, Champaign, v. 30, p. 493-8, 1995.

[28] YOU, C.-S., PARKER, R. S., GOODMAN, K. J., SWANSON, J. E., CORSO, T. N. Evidence of cis-trans isomerization of 9-cis- $\beta$-carotene during absorption in humans. Am. J. Clin. Nutr., Bethesda, v. 64, p. 177-83, 1996.

[29] YOU, C.-S., PARKER, R. S., GOODMAN, K., BRENNA, J. T., CANFIELD, W. Metabolism of $\left[{ }^{13} \mathrm{C}\right] 9-$ cis- $\beta$-carotene in humans. FASEB J., Bethesda, v. 8, n. 4, p. A422, 1994.

\section{6 - AGRADECIMENTOS}

Os autores agradecem à CAPES pelo suporte financeiro. 